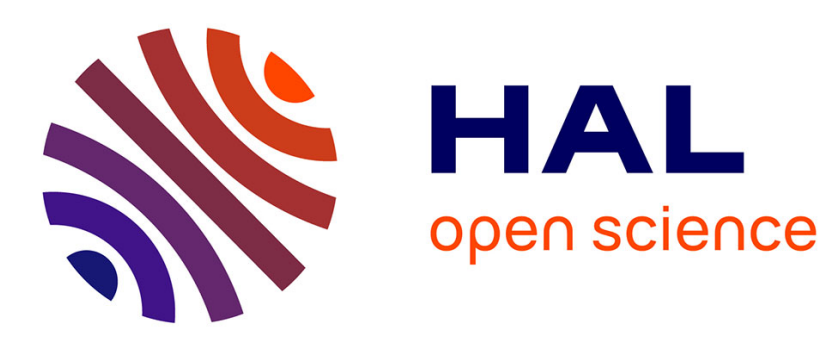

\title{
Older people and death-thought accessibility: The association between death and older people in memory
}

Valérian Boudjemadi, Alexandra Posner, Jennifer Bastart

\section{To cite this version:}

Valérian Boudjemadi, Alexandra Posner, Jennifer Bastart. Older people and death-thought accessibility: The association between death and older people in memory. Death Studies, 2020, pp.1-9. 10.1080/07481187.2020.1753852 . hal-02934985

\section{HAL Id: hal-02934985 \\ https://hal.science/hal-02934985}

Submitted on 9 Sep 2020

HAL is a multi-disciplinary open access archive for the deposit and dissemination of scientific research documents, whether they are published or not. The documents may come from teaching and research institutions in France or abroad, or from public or private research centers.
L'archive ouverte pluridisciplinaire HAL, est destinée au dépôt et à la diffusion de documents scientifiques de niveau recherche, publiés ou non, émanant des établissements d'enseignement et de recherche français ou étrangers, des laboratoires publics ou privés. 


\title{
Older people and death-thought accessibility: The association between death and older people in memory
}

\author{
Valęrian Boudjemadi ${ }^{\mathrm{a}}$, Alexandra Posner ${ }^{\mathrm{a}}$, and Jennifer Bastart ${ }^{\mathrm{b}^{*}}$

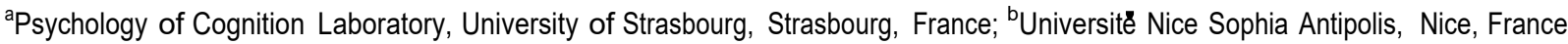

\begin{abstract}
This work aimed to conceptually replicate and extend Martens, Greenberg, Schimel, and Landau's findings about older people as threatening future self. We conducted two studies using a lexical decision task to measure death-thought accessibility. Results showed that older people primes lead to stronger facilitation of death-related compared, with negative words. Such a facilitation is not observed with young people primes (Study 1). Moreover, the automatic association between the representation of older people and death was stronger when participants and older people primes were of the same sex (Study 2). Implications of these findings with respect to ageism are discussed.
\end{abstract}

Due to increasing life expectancy and decreasing mortality and births, statistics show an unprecedented demographic evolution in the world, especially in Western societies: The population is ageing more quickly than ever in human history (United Nations, 2017). These demographic facts could have important consequences on intergenerational relationships and a spread of ageism. Ageism can be defined as a set of positive or negative prejudices, stereotypes, and discrimination toward older people (Iversen et al., 2009). Ageism is a widespread, pervasive phenomenon across cultures, with perpetrators of all ages (Fiske, 2017). It is already integrated during childhood (Bergman, 2017) and has many consequences for the older people, such as abuse by family and medical professionals (McDonald, 2017), discrimination at the workplace (Macdonald \& Levy, 2016), and decreasing cognitive performances, health, self-esteem, well-being, and longevity (Allen, 2016; Nelson, 2016a; Ng et al., 2016; Ramirez \& Palacios-Espinosa, 2016). Despite the importance of the age variable in social sciences (Nelson, 2016b; North \& Fiske, 2017), the prevalence of ageism (Abrams et al., 2011), and the aging of world population, research on prejudice, stereotypes, and discrimination refers mainly to gender and racial bias (Nelson, 2005; North \& Fiske, 2012). In such settings, developing research on age bias is crucial in order to understand how ageism operates, and how to reduce it.
Among research areas addressing the question of age bias against older people, the Terror Management Theory (TMT; Greenberg et al., 1986; Pyszczynski et al., 2010) offers an explanation about the deep roots of ageism (Greenberg et al., 2017). TMT posits that humans are steered toward survival while being fully aware that death is inescapable (Greenberg, 2012; Greenberg et al., 2008). Such a survival instinct paired with consciousness of the inevitability of death creates a deep anxiety (Pyszczynski et al., 2010). Consequently, many of human behaviors are motivated by the need to manage this profound death anxiety (Hayes et al., 2010). Aging is a natural process by which every individual gets closer to death across the lifespan. Since older people are the nearest to death compared to other age groups, they remind the younger of their own mortality (Martens et al., 2005). In this conceptualization, ageism would be a way to manage death anxiety by seeking distance from the death reminder: Older people (Greenberg et al., 2017). In line with this framework, we propose to extend previous research (Martens et al., 2004) and show that older people constitute a threat to future self because of the association between death and older people in memory.

Evidence supports the existence of a positive association between ageism and death anxiety (Bodner \& Cohen-Fridel, 2014; Depaola et al., 2003; Hunter et al., 1979). Ageism is also positively associated with aging anxiety, suggesting that fears regarding the

C્NTACT Valërian Boudjemad@ boudjemadi@unistra田 Faculty of Psychology, University of Strasbourg, 12 rue Goethe, Strasbourg, 67000, France. *Present address: Anthropology, Clinical, Cognitive, and Social Psychology Laboratory, Universite cOte d'Azur, Nice, France. 

continual process of aging are related with ageism (Allan et al., 2014). Moreover, the interaction between death anxiety and aging anxiety predicts ageism (Bodner et al., 2015).

Another body of studies focused on the association between the concept of death and the representation of older people in memory, as well as the attitudes adopted toward them (Martens et al., 2004). In their first study, Martens et al. (2004) exposed participants to pictures of older or young people, and then measured death-thought accessibility (DTA) with a word completion task (Greenberg et al., 1994). The results showed that participants exhibited significantly higher DTA when exposed to pictures of older people than when exposed to pictures of young people. In accordance with the authors' rationale, these results confirmed an association between the concepts of death and older people in memory.

Martens et al. (2004) further suggest that ageism would be a way to distance oneself from the threats older people represent. Indeed, an exposure to selfrelevant target may elicit derogation when these targets threat the integrity of the self. For instance, the well-known black sheep effect leads people to distance themselves from a deviant ingroup member that threats the positivity of the ingroup (Marques et al., 1988). According to some scholars, ageism may thus serve an ego-protection function: People derogate older people because they symbolize a threatening future ingroup they do not want to be part of (Nelson, 2005). The same reasoning underlies Martens et al.' hypothesis (2004, Study 3): People are motivated to derogate older people because they represent a threatening future self. Consequently, they explored attitudes toward older people following a mortality salience manipulation. Results indicated that under mortality salience, participants distanced more from older people than from young ones, while this difference did not emerge in the control condition. Moreover, they also showed that after a mortality salience manipulation, participants who perceived themselves as similar to older targets evaluated older people less positively in comparison to participants who perceived themselves as different from older targets. This mortality salience manipulation was replicated by Boudjemadi and Gana (2012) using an indirect measurement procedure and showed similar results. In the present paper, we intend to conceptually replicate and extend these findings by showing that the representation of older people (compared to young ones) triggers the concept of death in memory. Specifically, our research tests whether the link between death and representation of older people in memory is stronger when individuals perceive an old target as similar to the self.

Martens et al. (2004) claimed that ageism (1) is due to the mere association of older people and death representations in memory and (2) is reinforced by the perceived similarity with the older people target that is threatening. Despite the conceptual clarity of this reasoning, the first step (i.e., the association of older people and death representations in memory) has been weakly empirically demonstrated. The aim of the present paper is to reinforce this claim by conceptually replicating Martens and colleagues' findings (Study 1), and to provide evidence supporting the psychological mechanism explaining this link (Study 2).

\section{Study 1}

Martens et al. (2004, Study 1) used a word completion task to test the association of older people and death representations in memory. We aim to test the assumption of an automatic association between the concepts of death and older people in semantic memory by using a lexical decision task (LDT; Wittenbrink et al., 1997). We hypothesized an interaction between the priming type (i.e., old vs. young) and the target type (i.e., death-related words vs. negative words). Participants should respond faster to death-related words but not to negative words after being exposed to a subliminal old prime compared to a subliminal young prime. Here, the faster a participant recognizes death-related words, the more his/her DTA is elevated.

\section{Method}

\section{Participants}

We recruited 74 volunteers who were native Frenchspeakers, 40 women (54.10\%) and 34 men (45.90\%), ranged in age from 17 to 33 years (M $1 / 421.23$, SD $1 / 42.71)$. Most of the participants were students $(90.50 \%)$. The experiment is a 2 (priming type: Old vs. young) $\times 2$ (target type: Death-related words vs. negative words) within subject design. We estimated the sample size on the basis of previous work using a similar design (55 participants in Boccato et al., 2007). Power analysis indicated that this sample size is sufficient to detect a small to medium effect size with $95 \%$ power. 


\section{Procedure}

The session took place in a quiet room in a French university. Participants indicated their agreement to participate, and then completed a computer task presented as a study measuring the speed of word recognition in the presence of distractors. During the LDT, participants had to decide whether a string of letters was a legitimate French word or not. After the task, participants completed a debriefing questionnaire (Bargh \& Chartrand, 2000) to ensure they were not suspicious about the aim of the study, and were finally debriefed about the aim of the study.

We used Direct RT software for programing the LDT. On each trial, first a fixation point appeared in the center of the screen for $1000 \mathrm{~ms}$, followed by a prime presented for $16.67 \mathrm{~ms}$ (subliminal prime). A mask presented for $233.10 \mathrm{~ms}$ succeeded the prime and was followed by a target letter sequence. The target letter sequence remained on screen until the participant's response but no longer than $3000 \mathrm{~ms}$; participants had to respond by pressing one of two keys indicating if the letter sequence was a legitimate French word or not. Once the participant had responded, the next trial started after an inter-trial interval of $2 \mathrm{~s}$. In this study, stimulus onset asynchrony (SOA) was $249.77 \mathrm{~ms}$.

With respect to the materials used for the LDT, we used 3 prime words (old, young, table) and 40 target words (see Appendix A): Ten death-related words (e.g., skeleton), 10 negative words, which are not related to the concept of death (e.g., hate) and 20 nonwords (anagrams of the selected death-related and negative words). Death-related and negative words were pretested among 89 participants $(61$ women and 28 men) aged from 20 to 55 years (M $1 / 429.83$, SD $1 / 4$ 5.67). Results showed no statistically significant difference in the valence evaluation of the two word categories $\left(\mathrm{t}[88]^{1 / 4} 40.43, \mathrm{p} 1 / 4.67\right)$. After 10 practice trials, each target word (40) was associated once with each priming type (3), for a total of a 120 test trials.

\section{Measures}

Following Wittenbrink et al. (1997), only response latencies for target words were used in order to compute a facilitation/inhibition (F/I) score. We subtracted from the response latency for a given target word following the neutral prime, the response latency for the same target word following the old or young prime. Positive differences indicated facilitation and negative differences indicated inhibition. The more positive the difference was, the more it indicated a high degree of facilitation. Conversely, the more negative this difference was, the more it indicated a high degree of inhibition. Then, we computed mean F/I scores for: (1) negative words preceded by the old prime, (2) negative words preceded by the young prime, (3) death-related words preceded by the old prime and (4) deathrelated words preceded by the young prime. The more the F/I score for death-related words was high/low, the more the DTA was high/low.

\section{Results}

Preliminary analysis showed no outlying reaction times (under $150 \mathrm{~ms}$ and above $1500 \mathrm{~ms}$ ), but three participants were excluded due to extreme error percentage (higher than 20\%). We performed a 2 (priming type: Old vs. young) $\times 2$ (target type: Death-related words vs. negative words) repeated measures ANOVA on the mean F/I scores. Results revealed a significant main effect for the priming type $\left(F[1,70]^{1 / 4} 43.95, p<.0001\right.$, . $p^{2} 1 / 4.39$ ), with old primes (M $1 / 417.71 ;$ SD $1 / 438.09$ ) eliciting more facilitation than young primes (M 1/4 12.54; SD 1/4 38.18). Results also revealed a significant main effect for the target type ( $F[1,70] 1 / 412.84$, $\left.p<.0001, . p^{2} 1 / 4.15\right)$ showing that death related words' recognition ( $M \frac{1}{4} 17.52$; SD $\left.1 / 439.20\right)$ was facilitated in comparison to negative words' recognition (M $1 / 4-12.36 ;$ SD $1 / 455.70)$. These effects were qualified by the expected interaction $(F[1,70] 1 / 429.70, p<.0001$, . $\left.p^{2} 1 / 4.30\right)$. The mean F/I scores and standards deviation are displayed in Table 1.

Simple effects analysis with Bonferroni corrections (alpha of .05 divided by the number of non-orthogonal comparisons [i.e., 4]; the corrected alpha for simple effects is thus .0125) indicated a significant facilitation in the old prime condition for the recognition of death-related words compared to negative words $\left(\mathrm{t}[70]^{1 / 4} 5.96, p<.0001, \mathrm{~d} 1 / 41.06\right)$. However, this facilitation was not observed in the young prime condition (t[70] $1 / 4-0.08, \mathrm{p}^{1 / 4} 0.93, \mathrm{~d} 1 / 4-0.01$ ). These results replicated Martens and colleagues' finding

Table 1. Mean response facilitation/inhibition (ms) to death and negative words as a function of type of prime, relative to a neutral prime.

\begin{tabular}{lcc}
\hline & \multicolumn{2}{c}{ Target type } \\
\cline { 2 - 3 } & Death words & Negative words \\
\hline Priming type & $\mathrm{M}$ & $\mathrm{M}$ \\
Young & $-12.96_{\mathrm{a}}(45.69)$ & $-12.13_{\mathrm{a}}$ \\
& & $(66.01)$ \\
Old & $48.01_{\mathrm{b}}$ & $-12.60_{\mathrm{a}}$ \\
& $(52.25)$ & $(61.96)$ \\
\hline
\end{tabular}

Note. M $1 / 4$ mean. Numbers in parentheses represent the standard deviations. Means with different subscripts differ at a .05 significance level. 
(2004, Study 1). The representation of older people and death seem to be linked in semantic memory. Furthermore, the recognition of death-related words was significantly facilitated when preceded by older primes than young primes $(\mathrm{t}[70] 1 / 4-8.70, \mathrm{p}<.001$, d $1 / 4-1.24)$. No facilitation for the recognition of negative words in both conditions was observed ( $\mathrm{t}[70]$ $\left.1 / 4-0.06, \mathrm{p}^{1 / 4} .95, \mathrm{~d}^{1} / 40.01\right)$.

While the previous analyses compared response latencies for targets that followed relevant primes relative to trials preceded by neutral primes for the same targets, it is important to check whether these facilitations/inhibitions are also observed in an absolute sense by testing whether F/I means differ reliably from zero (Boccato et al., 2007). Facilitation for the recognition of death-related words following the old prime was statistically significant $\left(\mathrm{t}[70]_{1 / 47.74,} \mathrm{p}<.0001\right.$, $d 1 / 41.30$ ), whereas we observed only a tendency of inhibition for the recognition of negative words preceded by the same primes $(\mathrm{t}[70] 1 / 41.71, \mathrm{p} 1 / 4.09, \mathrm{~d} 1 / 4$ -0.28). Following young primes, in an absolute sense, recognition of death-related words was significantly

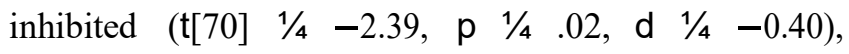
while the recognition of negative words was not ( $\mathrm{t}[70]$ $1 / 4-1.71, \mathrm{p} 1 / 4.13, \mathrm{~d} 1 / 4-0.26$ ). Importantly for our purpose, results showed that older people are strongly associated to death in absolute terms.

\section{Discussion}

We intended to replicate the results of the first study of Martens et al. (2004), showing an association of death and representation of older people in memory. We measured DTA with a LDT after subliminally exposing participants to old or young primes. As expected, old primes facilitate significantly the recognition of death-related words compared to young primes and compared to the recognition of negative targets. To put it differently, after subliminal exposures to the concept of older people, participants had higher DTA. These results are consistent with the results obtained by Martens et al. (2004) and indicate that the concept of aging and older people is strongly associated with the concept of death in memory.

\section{Study 2}

In line with previous research, we examined the association in memory between one's similarity to older people and death by using a LDT. We expected participants to respond faster to death-related words (but not to negative words) after being exposed to an older person of the same sex (congruent condition) than after exposure to an older person of the opposite sex (incongruent condition). We hypothesized an interaction between the priming type (i.e., congruent vs. incongruent), and the target type (i.e., deathrelated words vs. negative words). As in the previous study, the faster a participant recognizes death-related words, the higher the DTA.

\section{Method}

\section{Participants}

Participants were 123 volunteers who were native French-speakers, 63 women $(51.2 \%)$ and 60 men $(48.8 \%)$, ranged in age from 16 to 29 years (M $1 / 421.24$, SD $1 / 42.65)$. One hundred and twenty participants were students $(97.6 \%)$. The experiment is a 2 (priming type: Congruent vs. incongruent) $\times 2$ (target type: Death-related words vs. negative words) within subject design. We estimated the sample size on the basis of previous work using a similar design (112 participants in Boudjemadi et al., 2017). Power analysis indicated that this sample size is sufficient to detect a small to medium effect size with $95 \%$ power.

\section{Procedure}

The session took place in a French university. Participants were informed that the study measured the speed of word recognition in the presence of distracting pictures. Participants gave their agreement to participate and completed a LDT, in which they decided whether a string of letters was a legitimate French word or not. Following the LDT, participants answered a series of questions in order to verify that they did not perceive a link between primes and targets, as well as the real objective of the study and were debriefed (Bargh \& Chartrand, 2000).

We used Direct RT software for programing the LDT. On each trial, a fixation point appeared on the screen for $500 \mathrm{~ms}$, immediately followed by a prime presented for $150 \mathrm{~ms}$ (supraliminal prime), succeeded by a black screen for $50 \mathrm{~ms}$, followed by a target letter sequence. The letter string remained on screen for a maximum of $1500 \mathrm{~ms}$; once the participant had responded, an inter-trial interval of $1 \mathrm{~s}$ was introduced. In this LDT, SOA was $200 \mathrm{~ms}$.

As primes, three sets of black and white pictures were used: Four faces of older women, 4 faces of older men, and 4 casual objects. The sets of pictures portraying older women and older men were used in order to refer participants to an image of themselves 
in the future (see Appendix B). A supraliminal presentation was applied. Primes were followed rapidly by targets, which did not give participants the possibility to use conscious strategies for their decision (Wentura \& Degner, 2010). The pictures of older people were selected based on the standardization by Kennedy et al. (2009) using the criteria of neutral facial expression and estimated age of the depicted person. Neutral primes were selected based on their neutral valence from the International Affective Picture System (Lang et al., 2008). For the target words, 8 death-related words, 8 negative words, and 8 nonwords were selected based on the pretest presented in the first study. After 12 practice trials, each of the 24 target words was associated once with each priming type, for a total of a 288 test trials.

\section{Measures}

As in the first study and following Wittenbrink et al. (1997), only response latencies for target words were used in order to compute a F/I score. We subtracted from the response latency for a given target word following a neutral prime, the response latency for the same target word following an older man or older woman prime. Positive differences indicated facilitation and negative differences indicated inhibition. The more positive the difference was, the more it indicated a high degree of facilitation. Conversely, the more negative this difference was, the more it indicated a high degree of inhibition. Then, we computed mean F/I scores for: (1) negative words preceded by older primes of the same sex as the participants (congruent condition), (2) negative words preceded by older primes of the opposite sex from the participants (incongruent condition), (3) death-related words in congruent condition and (4) death-related words in incongruent condition. The more the $\mathrm{F} / \mathrm{I}$ score for death-related words was high/low, the more the DTA was high/low.

\section{Results}

No participant declared having perceived the purpose of the study. Out of the 123 participants, 4 were excluded due to a high number of errors (higher than $20 \%$ ). No outlying reaction times had to be excluded from results analyses. We performed a 2 (priming type: Congruent vs. incongruent) $\times 2$ (target type: Death-related words vs. negative words) repeated measures ANOVA on the mean F/I scores. The analyses revealed a marginal main effect for priming type
Table 2. Mean response facilitation/inhibition (ms) to death and negative words as a function of type of prime, relative to a neutral prime.

\begin{tabular}{lcc}
\hline & \multicolumn{2}{c}{ Target type } \\
\cline { 2 - 3 } & Death words & Negative words \\
\hline Priming type & $\mathrm{M}$ & $\mathrm{M}$ \\
Congruent & $20.02_{\mathrm{a}}$ & $1.78_{\mathrm{b}}$ \\
& $(34.57)$ & $(33.45)$ \\
Incongruent & $7.92_{\mathrm{b}}$ & $5.49_{\mathrm{b}}$ \\
& $(31.81)$ & $(30.84)$ \\
\hline
\end{tabular}

Note. M $1 / 4$ mean. Numbers in parentheses represent the standard deviations. Means with different subscripts differ at a .05 significance level.

$\left(F[1,118] \frac{1}{4} 4.76, p^{1 / 4} .055, p^{2} 1 / 4.03\right)$, with congruent primes (M $1 / 410.90$; SD $1 / 424.08$ ) eliciting more facilitation than incongruent primes (M $1 / 46.70 ;$ SD $1 / 423.43$ ). Results also revealed a significant main effect for target type $\left(F[1,118] 1 / 49.24, p \quad 1 / 4.003\right.$, , $\left.p^{2} \quad 1 / 4.07\right)$ showing that death related words' recognition ( $M \frac{1}{4} 13.97$; SD 1/4 29.57) was facilitated in comparison to negative words' recognition ( $M \frac{1}{4}$ 3.64; SD $1 / 425.74$ ). These effects were qualified by the expected interaction $\left(F[1,118] 1 / 411.53, p 1 / 4.001\right.$, , $\left.p^{2} 1 / 4.09\right)$. The mean $F / I$ scores and standard deviations are presented in Table 2.

Analyses of the simple effects with Bonferroni corrections indicated a significant facilitation of the recognition for death-related words compared to negative words in the congruent condition $(\mathrm{t}[118] 1 / 44.14, \mathrm{p}<.0001$, $d 1 / 40.54)$. This facilitation was not significant in the incongruent condition (t[118] 1/4 0.63, p 1 1 $40.53, \mathrm{~d} 1 / 40.08$ ). Furthermore, the recognition of death-related words in the congruent condition was significantly more facilitated in comparison with the incongruent condition $(t[118] 1 / 44.36, p<.0001, d 1 / 40.36)$. When comparing recognition facilitation for negative words in the congruent and the incongruent condition, no significant difference emerged (t[118] 1/4 - 1.05, p 1/4.30, d 1/4-0.11).

As in the first study, we decided to determine if facilitations are observed in an absolute sense. Results indicated a significant facilitation in the recognition of death-related words in the congruent condition $\left(\mathrm{t}[118]^{1 / 4} 6.32, \mathrm{p}<.0001, \mathrm{~d} 1 / 40.82\right)$, as well as in the incongruent condition $(\mathrm{t}[118] 1 / 42.71, \quad \mathrm{p} \quad 1 / 4.008$, $d 1 / 40.35$ ). Regarding the recognition of negative words, no facilitation was observed in the congruent condition (t[118]1/40.58, p 1/4.56, d 1/40.07), but there was a significant facilitated recognition in the incongruent condition (t[118]1/4 1.94, p 1/4 .05, d 1/40.25). These results corroborated our hypothesis: The representation of older people is associated with death in memory and this link is even stronger when the older person at hand is similar with the self. 


\section{Discussion}

In study 2, we intended to replicate and extend Martens and colleagues' findings (2004, Study 3), by showing that the similarity between participants and older people they were exposed to reinforces the association between older people and death in memory. Therefore, we measured DTA in a congruent condition where participants were exposed to pictures of older people of the same sex, and in an incongruent condition, where male participants were exposed to pictures of older women and female participants to pictures of older men. As hypothesized, the results showed that sex-congruent older primes significantly facilitated the recognition of death-related words compared to sex-incongruent older primes. The sex congruency of the prime did not impact the recognition of negative words. Furthermore, consistent with Martens et al. (2004), Nelson (2005) and Boudjemadi and Gana (2012), our results indicated that the association between the representation of older people and death in memory is stronger when participants shared a similarity with the older people they are exposed to.

\section{General discussion}

The present work focused on conceptual replication of studies dealing with the link between the representation of older people and death in memory. This link has been originally demonstrated in 2004 by Martens and colleagues. Our objective was to provide further evidence for the hypotheses that the representation of older people is associated with the concept of death in memory, especially when it represents a projection of oneself in the future.

Results of study 1 replicate those obtained in Martens et al. (2004, Study 1). The recognition of death-related words was significantly facilitated after subliminal presentation of words related to older people, compared to words related to young people. Furthermore, the facilitated recognition of deathrelated words, strong and significant also in an absolute sense, does not seem to be due to the negative valence of the idea of death, but to the concept of death itself. Taken together, these results show that DTA was induced by the concept of old age. Results of study 2 showed that the activation of the concept of death in memory was facilitated more when participants were exposed to a similar older target, compared to a dissimilar one. The (dis)similarity was introduced by the congruence/incongruence of the sex between the participants and the older people primes. In other words, the representation of an older woman is existentially more threatening for young women than an older man; the reverse is true for men. An important aspect of these studies is that all facilitations of death-related words (i.e., a higher DTA) were significant in an absolute sense: Older people are associated with death in memory, but this association is even stronger when the representation of an older person was similar to the participant.

\section{Limitations and future directions}

Our two studies are not free from limitations. First, the participants were not representative of the French population, and moreover they were not representative of the whole population of young people. Furthermore, the fact that most of the participants were young adults may have biased the observed link between the representation of older people and the concept of death. Thus, samples composed of middleaged adults and older people should be included in future studies.

Second, the choice of primes for the second study was limited to pictures of older people's faces, but it seems interesting to explore participants' deathassociation when confronted with the body of older people which is likely to be associated with specific fears. A complementary mechanism proposed by TMT to account for ageism is that the human body represents a source of existential anxiety reminding us of our animal nature as well as our vulnerability toward death (Goldenberg et al., 2009). Individuals are motivated to transcend the physicality of their human body by distancing from reminders of their animality (Goldenberg, 2005). Indeed, for instance, priming mortality led participants to view breastfeeding with more contempt (Cox et al., 2007). When reminded of the similarity between animals and humans, participants manifest more negative reactions toward pregnant women in comparison with nonpregnant women (Goldenberg et al., 2007) and manifest less interest for carnal dimension of sex under mortality salience (Goldenberg et al., 2002). Consequently, the representation of older people as having a degrading body is likely to remind younger people of their own animality, and thus to constitute a death reminder. Research showing the tendancy among younger people to animalisticaly dehumanize older people supports this reasoning (Boudjemadi et al., 2017).

Finally, as previously assumed (Nelson, 2005), ageist reactions are the result of the association in memory between death and the representation of 
older people, who are similar to the self because of a potential projection of the self to the future. Thus, ageism is not due to the fact that older people are an out group, but instead because they symbolize a future in group closer to death, existentially threatening. To test this hypothesis, it would be appropriate to use a morphing software and measure DTA following participants' representations of their own aging process and compare that to DTA following participants' representations of older persons in general.

\section{Conclusion}

To conclude, these two studies support the assumed process underlying the roots of ageism while opening new avenues for research dealing with age-based discrimination. Because of the aging of the entire population and especially in Western societies, and the negative consequences of ageism on older people, studying the consequences of exposure to older people and how to reduce the link between older persons and death in memory seems to become a public health priority.

\section{References}

Abrams, D., Russell, P. S., Vauclair, M., \& Swift, H. J. (2011). Ageism in Europe: Findings from the European social survey. Age UK.

Allan, L. J., Johnson, J. A., \& Emerson, S. D. (2014). The role of individual difference variables in ageism. Personality and Individual Differences, 59, 32-37. https://doi.org/10.1016/j.paid.2013.10.027

Allen, J. O. (2016). Ageism as a risk factor for chronic disease. The Gerontologist, 56(4), 610-614. https://doi.org/10.1093/geront/gnu158

Bargh, J. A., \& Chartrand, T. L. (2000). The mind in the middle. A practical guide to priming and automaticity research. In H. T. Ries \& C. M. Judd (Eds.), Handbook of research methods in social and personality psychology (pp. 253-285). Cambridge University Press.

Bergman, Y. S. (2017). Ageism in childhood. In T. D. Nelson (Ed), Ageism: Stereotyping and Prejudice against older persons (2nd ed., pp. 3-36). MIT Press.

Boccato, G., Cortes, B. P., Demoulin, S., \& Leyens, J. P. (2007). The automaticity of infrahumanization. European Journal of Social Psychology, 37(5), 987-999. https://doi.org/10.1002/ejsp.412

Bodner, E., \& Cohen-Fridel, S. (2014). The paths leading from attachment to ageism: A structural equation model approach. Death Studies, 38(7), 423-429. https://doi.org/10.1080/07481187.2013.766654

Bodner, E., Shrira, A., Bergman, Y. S., Cohen-Fridel, S., \& Grossman, E. S. (2015). The interaction between aging and death anxieties predicts ageism. Personality and Individual Differences, 86, 15-19. https://doi.org/10.1080/07481187. 2013.766654
Boudjemadi, V., Demoulin, S., \& Bastart, J. (2017). Animalistic dehumanization of older people by younger ones: Variations of humanness perceptions as a function of a target's age. Psychology and Aging, 32(3), 293-306. https://doi.org/10.1037/pag0000161

Boudjemadi, V., \& Gana, K. (2012). Effect of mortality salience on implicit ageism: Implication of age stereotypes and sex. European Review of Applied Psychology, 62(1), 9-17. https://doi.org/10.1016/j.erap.2011.11.002

Cox, C. R., Goldenberg, J. L., Arndt, J., \& Pyszczynski, T. (2007). Mother's milk: An existential perspective on negative reactions to breastfeeding. Personality and Social Psychology Bulletin, 33(1), 110-122. https://doi.org/10.1177/0146167206294202

Depaola, S. J., Griffin, M., Young, J. R., \& Neimeyer, R. A. (2003). Death anxiety and attitudes toward the elderly among older adults: The Role of gender and ethnicity. Death Studies, 27(4), 335-354. https://doi.org/10.1080/07481180302904

Fiske, S. T. (2017). Prejudices in cultural contexts: Shared stereotypes (gender, age) versus variable stereotypes (race, ethnicity, religion). Perspectives on Psychological Science, 12(5), 791-799. https://doi.org/10.1177/1745691617708204

Goldenberg, J. L. (2005). The body stripped down: An existential account of ambivalence toward the physical body. Current Directions in Psychological Science, 14(4), 224-228. https://doi.org/10.1111/j.0963-7214.2005.00369.x

Goldenberg, J. L., Cox, C. R., Arndt, J., \& Goplen, J. (2007). Viewing" pregnancy as existential threat: The effects of creatureliness on reactions to media depictions of the pregnant body. Media Psychology, 10(2), 211-230. https://doi.org/10.1080/15213260701375629

Goldenberg, J. L., Cox, C. R., Pyszczynski, T., Greenberg, J., \& Solomon, S. (2002). Understanding human ambivalence about sex: The effects of stripping sex of meaning. Journal of Sex Research, 39(4), 310-320. https://doi.org/10.1080/00224490209552155

Goldenberg, J. L., Heflick, N., Vaes, J., Motyl, M., \& Greenberg, J. (2009). Of mice and men, and objectified women: A terror management account of infrahumanization. Group Processes \& Intergroup Relations, 12(6), 763-776. https://doi.org/10.1177/1368430209340569

Greenberg, J. (2012). Terror management theory: From genesis to revelations. In P. R. Shaver \& M. Mikulincer (Eds.), Meaning, mortality, and choice: The social psychology of existential concerns (pp. 17-35). American Psychological Association.

Greenberg, J., Helm, P., Maxfield, M., \& Schimel, J. (2017). How our mortal fate contributes to ageism: A terror management perspective. In T. D. Nelson (Ed.), Ageism: Stereotyping and prejudice against older persons (pp. 105-132). MIT Press.

Greenberg, J., Pyszczynski, T., \& Solomon, S. (1986). The causes and consequences of a need for self-esteem: A terror management theory. In R. F. Baumeister (Ed.), Public self and private self (pp. 188-212). Springer.

Greenberg, J., Pyszczynski, T., Solomon, S., Simon, L., \& Breus, M. (1994). Role of consciousness and accessibility of death-related thoughts in mortality salience effects. Journal of Personality and Social Psychology, 67(4), 627-637. https://doi.org/10.1037/0022-3514.67.4.627

Greenberg, J., Solomon, S., \& Arndt, J. (2008). A basic but uniquely human motivation. In J. Y. Shah \& W. L. 
Gardner (Eds.), Handbook of motivation science (pp. 114-134). Guilford.

Hayes, J., Schimel, J., Arndt, J., \& Faucher, E. H. (2010). A theoretical and empirical review of the death-thought accessibility concept in terror management research. Psychological Bulletin, 136(5), 699-739. https://doi.org/10.1037/a0020524

Hunter, K., Linn, M. W., \& Pratt, T. C. (1979). Minority women's attitudes about aging. Experimental Aging Research, 5(2), 95-108. https://doi.org/10.1080/03610737908257190

Iversen, T. N., Larsen, L., \& Solem, P. E. (2009). A conceptual analysis of ageism. Nordic Psychology, 61(3), 4-22. https://doi.org/10.1027/1901-2276.61.3.4

Kennedy, K. M., Hope, K., \& Raz, N. (2009). Lifespan adult faces: Norms for age, familiarity, memorability, mood, and picture quality. Experimental Aging Research, 35(2), 268-275. https://doi.org/10.1080/03610730902720638

Lang, P. J., Bradley, M. M., \& Cuthbert, B. N. (2008). International affective picture system (IAPS): Affective ratings of pictures and instruction manual. University of Florida.

Macdonald, J. L., \& Levy, S. R. (2016). Ageism in the workplace: The role of psychosocial factors in predicting job satisfaction, commitment, and engagement. Journal of Social Issues, 72(1), 169-190. https://doi.org/10.1111/josi.12161

Marques, J. M., Yzerbyt, V. Y., \& Leyens, J. P. (1988). The "black sheep effect": Extremity of judgments towards ingroup members as a function of group identification. European Journal of Social Psychology, 18(1), 1-16. https://doi.org/10.1002/ejsp.2420180102

Martens, A., Goldenberg, J. L., \& Greenberg, J. (2005). A terror management perspective on ageism. Journal of Social Issues, 61(2), 223-239. https://doi.org/10.1111/j.1540-4560. 2005.00403.x

Martens, A., Greenberg, J., Schimel, J., \& Landau, M. J. (2004). Ageism and death: Effects of mortality salience and perceived similarity to elders on reactions to elderly people. Personality and Social Psychology Bulletin, 30(12), 1524-1535. https://doi.org/10.1177/0146167204271185

McDonald, L. (2017). Ageism and elder mistreatment: Talking the talk but not walking the walk. In T. D. Nelson (Ed.), Ageism: Stereotyping and prejudice against older persons (pp. 135-163). MIT Press.
Nelson, T. D. (2005). Ageism: Prejudice against our feared future self. Journal of Social Issues, 61(2), 207-221. https://doi.org/10.1111/j.1540-4560.2005.00402.x

Nelson, T. D. (2016a). Promoting healthy aging by confronting ageism. American Psychologist, 71(4), 276-282. https://doi.org/10.1037/a0040221

Nelson, T. D. (2016b). The age of ageism. Journal of Social Issues, 72(1), 191-198. https://doi.org/10.1111/josi.12162

Ng, R., Allore, H. G., Monin, J. K., \& Levy, B. R. (2016). Retirement as meaningful: Positive retirement stereotypes associated with longevity. Journal of Social Issues, 72(1), 69-85. https://doi.org/10.1111/josi.12156

North, M. S., \& Fiske, S. T. (2012). An inconvenienced youth? Ageism and its potential intergenerational roots. Psychological Bulletin, 138(5), 982-997. https://doi.org/10.1037/a0027843

North, M. S., \& Fiske, S. T. (2017). Succession, consumption, and identity: Prescriptive ageism domains. In T. D. Nelson (Ed.), Ageism: Stereotyping and prejudice against older persons (pp. 77-104). MIT Press.

Pyszczynski, T., Greenberg, J., Koole, S., \& Solomon, S. (2010). Experimental existential psychology: coping with the facts of life. In S. T. Fiske, \& D. T. Gilbert (Eds.), The handbook of social psychology (pp. 724-757). Wiley.

Ramirez, L., \& Palacios-Espinosa, X. (2016). Stereotypes about old age, social support, aging anxiety and evaluation of one's own health. Journal of Social Issues, 72(1), 47-68. https://doi.org/10.1111/josi.12155

United Nations (2017). World Population Ageing. United Nations. https://www.un.org/en/development/desa/population/theme/ageing/WPA2017.asp

Wentura, D., \& Degner, J. (2010). Practical guide to sequential priming and related tasks. In B. Gawronski, \& B. K. Payne (Eds.), Handbook of implicit social cognition: Measurement, theory, and applications. (pp. 95-116). Guilford.

Wittenbrink, B., Judd, C. M., \& Park, B. (1997). Evidence for racial prejudice at the implicit level and its relationship with questionnaire measures. Journal of Personality and Social Psychology, 72(2), 262-274. https://doi.org/10.1037//0022-3514.72.2.262 
Appendix A. List of words used during the lexical decision task

\begin{tabular}{lllr}
\hline Morbid & Study & Negative & Study \\
\hline Cadaver (cadavre) & $1 \& 2$ & Rape (viol) & $1 \& 2$ \\
Death (mort) & $1 \& 2$ & Hit (frapper) & 1 \\
Skeleton (squelette) & $1 \& 2$ & Beat (battre) & $1 \& 2$ \\
Grave (tombe) & $1 \& 2$ & Violence (violence) & $1 \& 2$ \\
Funereal (funěbre) & $1 \& 2$ & Hate (haine) Cruelty & $1 \& 2$ \\
Funeral (funërailles) & $1 \& 2$ & (cruautë) Aggression & $1 \& 2$ \\
Cemetery (cimetiêre) & 1 & (agression) & $1 \& 2$ \\
Die (mourir) & $1 \& 2$ & Torture (torture) & 1 \\
Passing (dëcěs) & $1 \& 2$ & Humiliate (humilier) & $1 \& 2$ \\
Tomb (tombeau) & 1 & Devour (dèvorer) & $1 \& 2$ \\
\hline
\end{tabular}

Note: words between parentheses correspond to the French words used in studies 1 and 2.

Appendix B. Pictures used during the lexical decision task in study 2
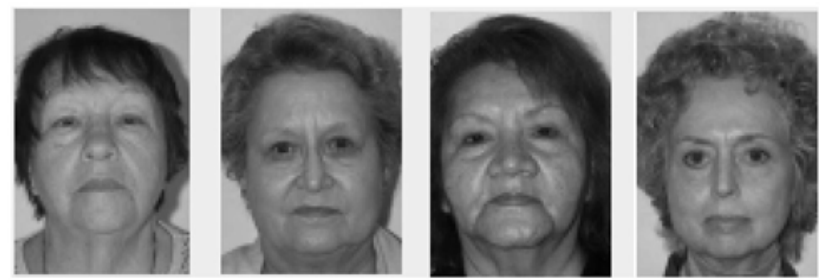

Figure B.1. Older people women pictures.
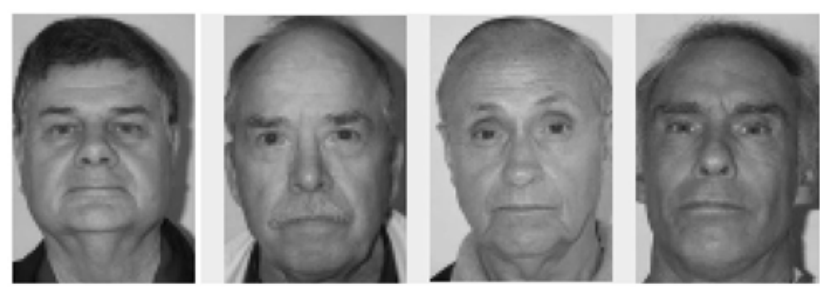

Figure B.2. Older people men pictures.
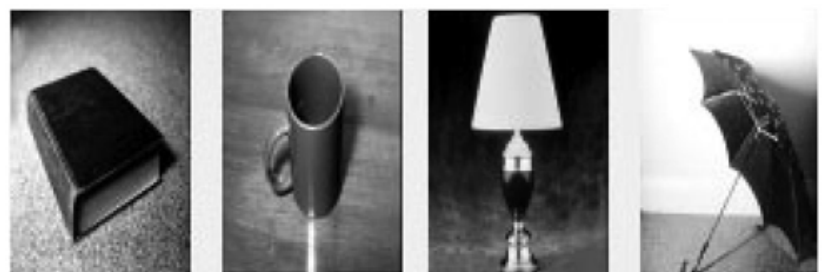

Figure B.3. Neutral pictures. 